\title{
$\begin{array}{ll}\text { Research Square } & \text { Preprints are preliminary reports that have not undergone peer review. } \\ \text { They should not be considered conclusive, used to inform clinical practice, } \\ \text { or referenced by the media as validated information }\end{array}$
}

\section{Multidisciplinary Approach in COVID-19 Pneumonia: A Backward Path by an Expert Team}

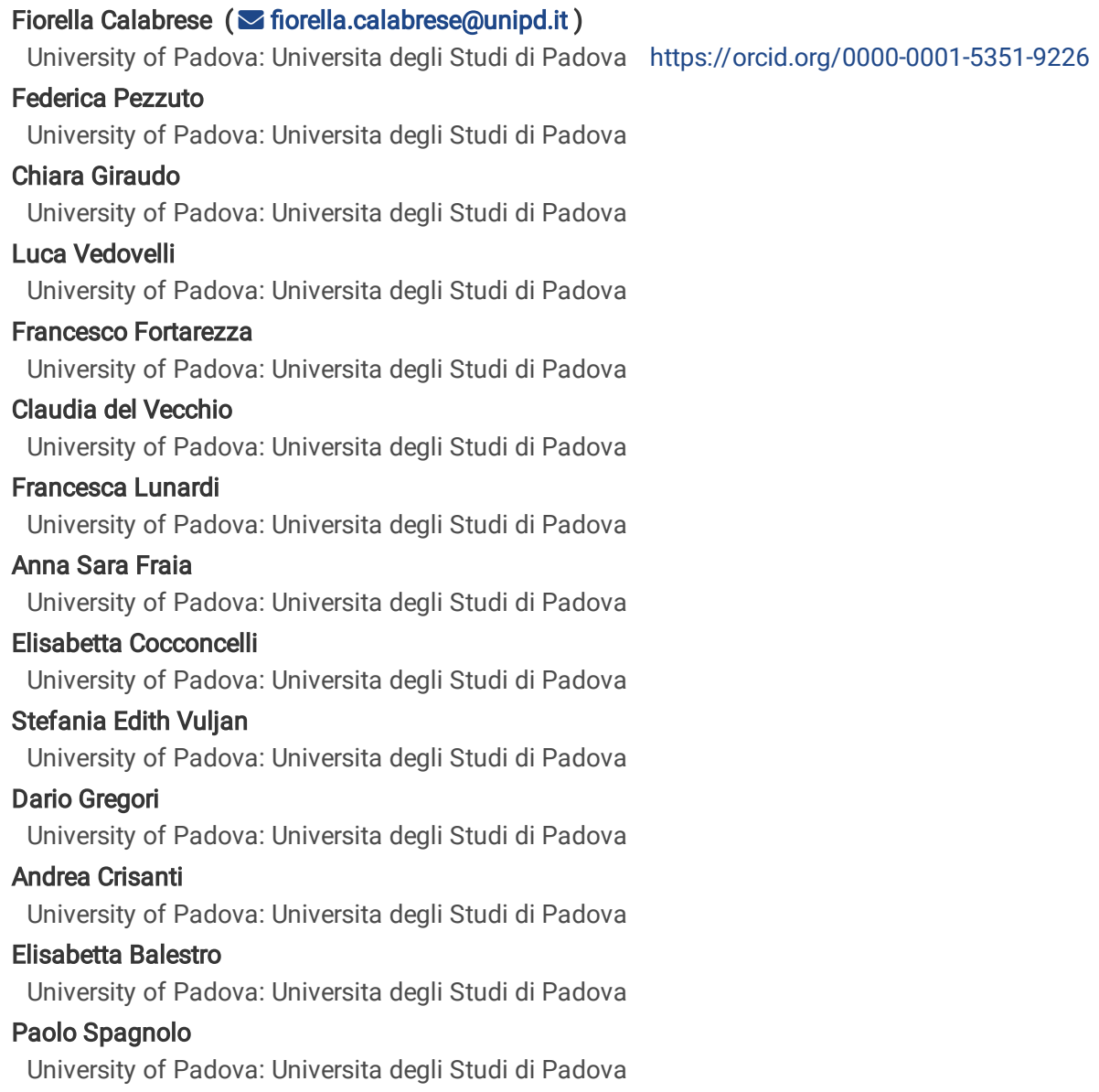

\section{Research}

Keywords: multidisciplinary approach, COVID-19 pneumonia, SARS-Cov-2

Posted Date: December 2nd, 2020

DOI: https://doi.org/10.21203/rs.3.rs-116735/v1

License: (c) (7) This work is licensed under a Creative Commons Attribution 4.0 International License. Read Full License 


\section{Abstract}

Background: The novel coronavirus disease 2019 (COVID-19) represents a medical challenge worldwide. COVID-19 pneumonia is an extremely complex disease. The hypothesis of the study was that a multidisciplinary approach involving experienced specialists in diffuse parenchymal lung disease might improve the diagnosis of patients with COVID-19 pneumonia.

Methods: Two pulmonologists, two radiologists, and two pathologists reviewed 27 patients who died of severe COVID-19 pneumonia as the main diagnosis made by non-pulmonologists. To evaluate whether the contribution of specialists, individually and/or in combination, might modify the original diagnosis, a three-step virtual process was planned. Pulmonologists, radiologists and pathologists were asked to classify every case into four distinct levels of diagnostic certainty, based on clinical, radiological, and morphological/virologic data obtained from an autoptic lung sample, respectively. The whole lung examination was considered the gold standard for the final diagnosis. The probability of a correct diagnosis was calculated, and the effectiveness of a multidisciplinary diagnosis was obtained by comparing diagnoses made by experienced pulmonologists with those made by non-pulmonologists.

Results: COVID-19 pneumonia was excluded in 2 cases (8\%) and was a marginal feature in 3 cases (11\%). The probability of a correct diagnosis increased strikingly from an undedicated clinician to an expert specialist, becoming progressively more accurate at different steps. Every single specialist made significantly more correct diagnoses than any non-pulmonologist. The highest level of accuracy was achieved by the combination of 3 expert specialists.

Conclusions: In summary, the dynamic interaction between expert specialists significantly improves the diagnostic confidence and management of patients with COVID-19 pneumonia.

\section{Background}

Coronavirus disease 19 (COVID-19) was first identified in Wuhan, China, in December 2019 and is now on its second wave. Genetic sequencing of the virus determined that it is a beta coronavirus named severe acute respiratory syndrome-related coronavirus 2 (SARS-CoV-2) [1]. Although most patients have a favorable prognosis, pneumonia, and severe hypoxemia secondary to SARS-CoV-2 infection can lead to acute respiratory failure (ARF) and death [2]. Elderly male patients with comorbidities such as obesity, hypertension, diabetes, cardiac disease, and neoplasm also have an increased risk for severe disease and death and need distinct management and higher surveillance levels [3-6]. Management remains suboptimal with high mortality rates, particularly among patients admitted to the intensive care unit (ICU).

The integration of all available data from each patient has proven crucial in the management of diffuse parenchymal lung disease (DPLD). Indeed, the international guidelines suggest health professionals with experience in DPLD be involved in patient diagnosis and management in a multidisciplinary approach to achieve the most confident diagnosis and optimize treatment [7]. The sudden onset and rapid spread of the COVID-19 pandemic with the high number of infections and deaths have led to a global health emergency. Since this was an unknown disease, the priority has been stemming the infection, which inevitably has limited interaction among experts. As COVID-19 is an extremely complex disease, it would potentially benefit from a multidisciplinary approach even during the pandemic. The hypothesis of this study was therefore that a multidisciplinary approach involving specialists experienced in DPLD (pulmonologists, radiologists, and pathologists) may improve the diagnosis and management of patients with COVID-19 pneumonia, following a decisionmaking approach similar to what is used in DPLD.

\section{Methods Study subjects}

The present study was a critical re-evaluation of deceased patients by an expert team of specialists (pulmonologists, radiologists, and pathologists) routinely involved in multidisciplinary meetings of mainly DPLD [8] but also with robust experience in COVID-19 diagnosis and management [9, 10]. We retrospectively studied 27 patients who consecutively died from March to May 2020 in our hospital of severe COVID-19 pneumonia as the main diagnosis made by nonpulmonologists (i.e. emergency room clinicians, general practitioners, specialists in infectious diseases, and anaesthesiologists).

At autopsy, the whole lungs were macroscopically examined, and a small sample was taken from the most representative area of lung injury. The sample was in part preserved in RNA later and processed for molecular analyses (see below for molecular processing details) and in part fixed in formalin for routine histology. Pathological features suggestive of COVID-19 pneumonia (alveolar injury as well as vascular lesions) were quantitatively described using a scoring system, as previously reported [10]. Other associated lesions (neoplasia, infectious diseases, aspiration pneumonia, etc.) were also reported. To confirm the pathological diagnosis of COVID-19 pneumonia, the fragment preserved in RNA later was also processed by real time reverse transciptase-polymerase chain reaction (RT-PCR) for SARS-CoV2 [SARS-CoV-2 (2019-nCoV) Centers for Disease Control and Prevention (CDC) Emergency Use Authorized (EUA) Authorized qPCR probe assay primer/probe mix]. An additional fragment was analyzed by culture, as previously described [11]. In order to define the levels of certainty for a diagnosis of COVID-19 pneumonia, two expert pathologists (F.C., F.P.) scored all cases independently and blinded to clinical and autopsy data. Based on morphological/virologic evaluation, four distinct levels of diagnostic certainty were defined: 1) Definite COVID-19 pneumonia: all lung samples showing lesions typical of COVID-19 pneumonia (vascular injury and/or diffuse alveolar damage/organizing pneumonia), confirmed SARS-CoV2 lung positivity (both molecular and culture), without other lesions suggestive of alternative diagnoses, 2) Probable COVID-19 pneumonia: lung samples displaying mainly features of COVID-19 pneumonia (+/- lung SARS-CoV2 infection) with other associated lesions (i.e. foci of bacterial infection, 3) Possible COVID-19 pneumonia: lung samples showing only focal changes of COVID-19 pneumonia (+/- lung SARS-CoV2 infection, etc.) with more extensive features consistent with alternative diagnoses (i.e., lung cancer/metastasis, etc.) 4) Non-COVID-19 pneumonia: lung samples not showing any typical lesions, no evidence of SARS-CoV2 infection, and no presence of features consistent with alternative diagnoses. 
During the autopsy, additional fragments were sampled from both lungs (at least 20 samples for each case) and systematically analyzed, as previously described [12].

Clinical evaluation was performed by two experienced pulmonologists (P.S., E.B.) based on the following data: past and recent medical history including comorbidities, respiratory and systemic signs and symptoms (type and duration) before hospital admission, imaging, laboratory findings, gas exchange values (FiO2, pO2, and p02/FiO2) and their changes during hospitalization, and oxygen supplementation. Based on this data, patients were classified as follows: 1) Definite COVID-19 pneumonia: clinical findings typical of COVID-19 such as severe acute respiratory illness (i.e., fever, cough, shortness of breath, hypoxemia) in the absence of an alternative diagnosis that could explain the clinical presentation [13, 14]; 2) Probable COVID-19 pneumonia: features of COVID-19 pneumonia associated with findings suggestive of alternative diagnoses (e.g., pleural effusion, clinical and laboratory findings in keeping with heart failure, or signs of bacterial pneumonia), 3) Possible COVID-19 pneumonia: features of COVID-19 pneumonia associated with prevalent findings consistent with alternative etiologies (e.g., lung cancer, pulmonary metastases, pulmonary edema, heart failure), 4) Non-CoVID-19 pneumonia: absence of typical signs/symptoms and laboratory findings of COVID-19 pneumonia in the presence of features consistent with alternative diagnoses (e.g., neoplasm, interstitial lung disease, ischemic heart disease, pulmonary edema).

With regard to the radiological assessment, all chest X-rays and, when available, chest computed tomography (CT) images were assessed by two expert thoracic radiologists (C.G., A.F.). According to the radiological findings, patients were classified as follows: 1) Definite COVID 19 pneumonia: typical findings of COVID-19 pneumonia, such as bilateral ground-glass opacities and/or consolidations [15], without any signs of alternative diagnoses; 2) Probable CoVID-19 pneumonia: features of COVID-19 pneumonia associated with abnormalities such as pleural effusion, cardiomegaly, or Kerley B lines suggestive of cardiac failure, or lobar consolidation suggestive of bacterial pneumonia; 3) Possible COVID-19 pneumonia: features of COVID-19 pneumonia associated with predominant findings of alternative diagnoses (e.g., unilateral pulmonary lesions due to lung cancer, pulmonary bilateral metastatic nodules), 4) Non-COVID19 pneumonia: no typical signs of COVID-19 with features suggestive of alternative diagnoses (e.g., unilateral pulmonary lesions due to lung cancer, reticular changes secondary to interstitial lung disease).

Data regarding demographics, smoking history, symptoms, comorbidities, treatment, disease duration, serology, radiological and pathological findings were included in a dedicated database in REDCap. Informed consent was granted by a relative/legal representative of each deceased patient. The study was approved by the local clinical institutional review Board.

\section{Study design}

To evaluate whether the contribution of pulmonologists, radiologists, and pathologists individually and/or in combination, could change the diagnosis originally made by non-pulmonologists, we planned a three-step process, modifying the methodology previously used in the evaluation of patients with DPLD [16].

Briefly, in the first step, two pulmonologists (P.S., E.B.) and two radiologists (C.G., A.F.) independently reviewed clinical and radiological data for each patient, without pathological data, and recorded their individual diagnoses and confidence levels. In the second step, pulmonologists and radiologists discussed their diagnosis and again recorded their individual or shared (in case of disagreement) confidence level. During the third step, pathologists entered the arena and reported the pathological diagnosis performed on a single lung fragment. The final diagnosis derived from the whole lung examination and full organ autopsy and was considered the diagnostic gold standard. Virtual meetings via the Zoom platform were set to allow pulmonologists, radiologists, and pathologists to discuss their interpretation with mutual collaboration (Fig. 1).

\section{Analysis}

All patients were evaluated by pulmonologists and pathologists. One case was not evaluated by radiologists due to lack of radiological data. Specialist scores (for single specialist and for combinations of different specialists) were compared with the full autopsy diagnosis, that was considered to be the true diagnosis, and were recorded as "correct" or "wrong". Probability of a correct diagnosis ( $95 \%$ confidence interval) was calculated with the method of Wilson using the binconf function of the R package $\{\mathrm{Hmisc}\}[17]$. To explore the effectiveness of a multidisciplinary diagnosis we compared specialist diagnoses with the non-pulmonologist using a model based on generalized estimating equations (GEE) [18] which expand the application of generalized linear models, providing a framework for analyzing correlated data, especially from repeated measures studies where multiple observations are collected from a specific sampling unit [19]. In particular, we used a first-order autoregressive correlation structure and a robust standard error estimation to fit our small sample size. The R package \{geepack\} was used for the analysis [20]. We exponentiated GEE results to obtain an odds ratio (95\% $\mathrm{Cl}$ ) for each specialist (or combination of specialists) on their ability to formulate a correct diagnosis. All analyses and plotting were conducted on R software v.4.0.2 [21]. The full code used for the analysis is available upon request.

\section{Results \\ Study population}

For all patients, demographic, clinical, and laboratory data are summarized in Table 1 . The patient population included 15 males (56\%) and 12 females (44\%) with a median age of 82 years (overall range 42-97 years, interquartile range, 75.5-87.5 years). At disease onset, the main common complaints were dyspnea (89\%), fever (74\%), and cough (67\%). On admission, white blood cells (WBC), and lymphocytes showed a median value of $2 \times 109 / \mathrm{L}$ (overall range $0.99-20.36$ $\times 109 / \mathrm{L}$, interquartile range $4.14-12.90 \times 109 / \mathrm{L}$ ) and $0.79 \times 109 / \mathrm{L}$ (overall range $0.4-1.69 \times 109 / \mathrm{L}$, interquartile range $0.6425-1.0375 \times 109 / \mathrm{L}$ ), respectively . D-dimer levels were available for 19 patients, with a median value of $497 \mu \mathrm{g} / \mathrm{L}$ (overall range $150-3250 \mu \mathrm{g} / \mathrm{L}$, interquartile range $281-1216 \mu \mathrm{g} / \mathrm{L}$ ). 
Table 1

Main clinical, epidemiological and laboratory data available for all patients.

\begin{tabular}{|c|c|c|c|c|c|c|c|c|c|c|c|c|c|}
\hline \multirow[t]{3}{*}{ ID } & \multicolumn{3}{|c|}{$\begin{array}{l}\text { EPIDEMIOLOGICAL } \\
\text { DATA }\end{array}$} & & \multicolumn{3}{|c|}{ SYMPTOMS } & \multicolumn{4}{|c|}{$\begin{array}{l}\text { LABORATORY } \\
\text { TESTS }\end{array}$} & \multirow{3}{*}{$\begin{array}{l}\text { Symptoms before admission } \\
\text { Days }\end{array}$} & \multirow[t]{3}{*}{ Ward } \\
\hline & Sex & Age & Smoke & Comorbidities* & Fever & Cough & Dispnea & WBC & LY & LY & D-D & & \\
\hline & & yrs & & & $c^{\circ}$ & & & $10^{9} / \mathrm{L}$ & $10^{9 / L}$ & $\%$ & $\mu g / L$ & & \\
\hline 1 & M & 82 & no & 2 & 39.5 & yes & yes & 15.17 & 0.79 & 5.2 & 311 & 5 & ICU \\
\hline 2 & $\mathrm{~F}$ & 69 & na & 2 & 37.9 & no & yes & 8.94 & 1.09 & 12.2 & 2063 & 5 & ICU \\
\hline 3 & $M$ & 76 & na & 3 & 38 & no & yes & 9.14 & 1.02 & 7.9 & 736 & 3 & ICU \\
\hline 4 & $M$ & 71 & no & 1 & 38 & yes & no & 17.98 & 1.69 & 9.4 & 684 & 14 & ICU \\
\hline 5 & $\mathrm{~F}$ & 87 & former & 4 & 39 & no & yes & 13.15 & 0.65 & 4.9 & 2929 & 3 & Non ICU \\
\hline 6 & $M$ & 79 & yes & 3 & 37.6 & yes & yes & 2.68 & 0.62 & 23.1 & 450 & 2 & ICU \\
\hline 7 & $M$ & 85 & former & 5 & 38 & yes & yes & 18.09 & 0.79 & 4.4 & 772 & 4 & Non ICU \\
\hline 8 & $M$ & 76 & no & 2 & 38 & no & yes & 5.28 & 1.36 & 25.8 & 150 & 0 & ICU \\
\hline 9 & $\mathrm{~F}$ & 86 & no & 5 & $<37$ & no & yes & 12.16 & 0.83 & 6.8 & na & 5 & Non ICU \\
\hline 10 & M & 96 & no & 5 & $<37$ & no & yes & 4.99 & 1.63 & 32 & 150 & 2 & Non ICU \\
\hline 11 & M & 86 & no & 4 & 38.6 & yes & yes & 2.7 & 0.4 & 14.3 & 3250 & 3 & Non ICU \\
\hline 12 & M & 77 & no & 3 & 39 & yes & yes & 4.08 & 0.81 & 19.9 & 497 & 18 & ICU \\
\hline 13 & $\mathrm{~F}$ & 90 & no & 4 & 39 & yes & yes & 17.83 & 0.77 & 4.3 & na & 7 & Non ICU \\
\hline 14 & M & 80 & no & 4 & 38.5 & yes & yes & 0.99 & na & na & na & 2 & Non ICU \\
\hline 15 & $\mathrm{~F}$ & 73 & na & 1 & 37.8 & no & yes & 5.52 & 0.67 & 12.2 & 345 & 2 & ICU \\
\hline 16 & $M$ & 61 & yes & 3 & $<37$ & no & yes & 3.02 & na & na & na & 5 & ICU \\
\hline 17 & $M$ & 82 & former & 6 & 38 & yes & yes & 3.72 & 0.46 & 12.4 & 1711 & 3 & Non ICU \\
\hline 18 & $M$ & 75 & no & 0 & 38.5 & yes & yes & 5.48 & 0.49 & 9.8 & 370 & 7 & ICU \\
\hline 19 & $M$ & 95 & former & 3 & $<37$ & yes & yes & 20.36 & 1.24 & 6.1 & 176 & 2 & Non ICU \\
\hline 20 & $\mathrm{~F}$ & 88 & no & 5 & 38.5 & yes & yes & 6.45 & 0.94 & 14.6 & 251 & 4 & Non ICU \\
\hline 21 & $\mathrm{~F}$ & 74 & former & 3 & 38 & yes & yes & 5.2 & 0.8 & 15.4 & 150 & 10 & ICU \\
\hline 22 & $\mathrm{~F}$ & 87 & no & 3 & 37 & yes & yes & 2.6 & 0.49 & 18.6 & 644 & 8 & Non ICU \\
\hline 23 & $\mathrm{~F}$ & 92 & na & 2 & 38.5 & no & no & 16.37 & 0.95 & 5.8 & 1660 & 2 & Non ICU \\
\hline 24 & $\mathrm{~F}$ & 90 & na & 3 & 37.7 & yes & yes & na & na & na & na & 1 & Non ICU \\
\hline 25 & $M$ & 83 & former & 1 & $<37$ & yes & yes & 5.78 & 0.61 & 10.6 & na & 6 & Non ICU \\
\hline 26 & $\mathrm{~F}$ & 97 & na & 3 & 37.9 & yes & no & 7.37 & 1.49 & 75.4 & na & 0 & Non ICU \\
\hline 27 & $\mathrm{~F}$ & 42 & na & 1 & $<37$ & no & yes & 4.32 & 0.70 & 16.2 & na & 33 & Non ICU \\
\hline
\end{tabular}

\section{Multistep process and interobserver agreement}

During the first step (Individual diagnosis by Radiologists and Pulmonologists), pulmonologists categorized 11 cases as definite (41\%), 9 cases as probable (33\%), 3 cases as possible (11\%), and 4 as non-COVID-19 pneumonia (15\%). Radiologists classified 11 patients as definite (42\%), 11 patients as probable (42\%), 2 patients as possible (8\%) and 2 patients as non-COVID-19 pneumonia (8\%). The radiological data of one patient was not available. The overall diagnoses with their corresponding level of confidence are reported in Table 2. 
Table 2

Confident diagnoses achieved step by step.

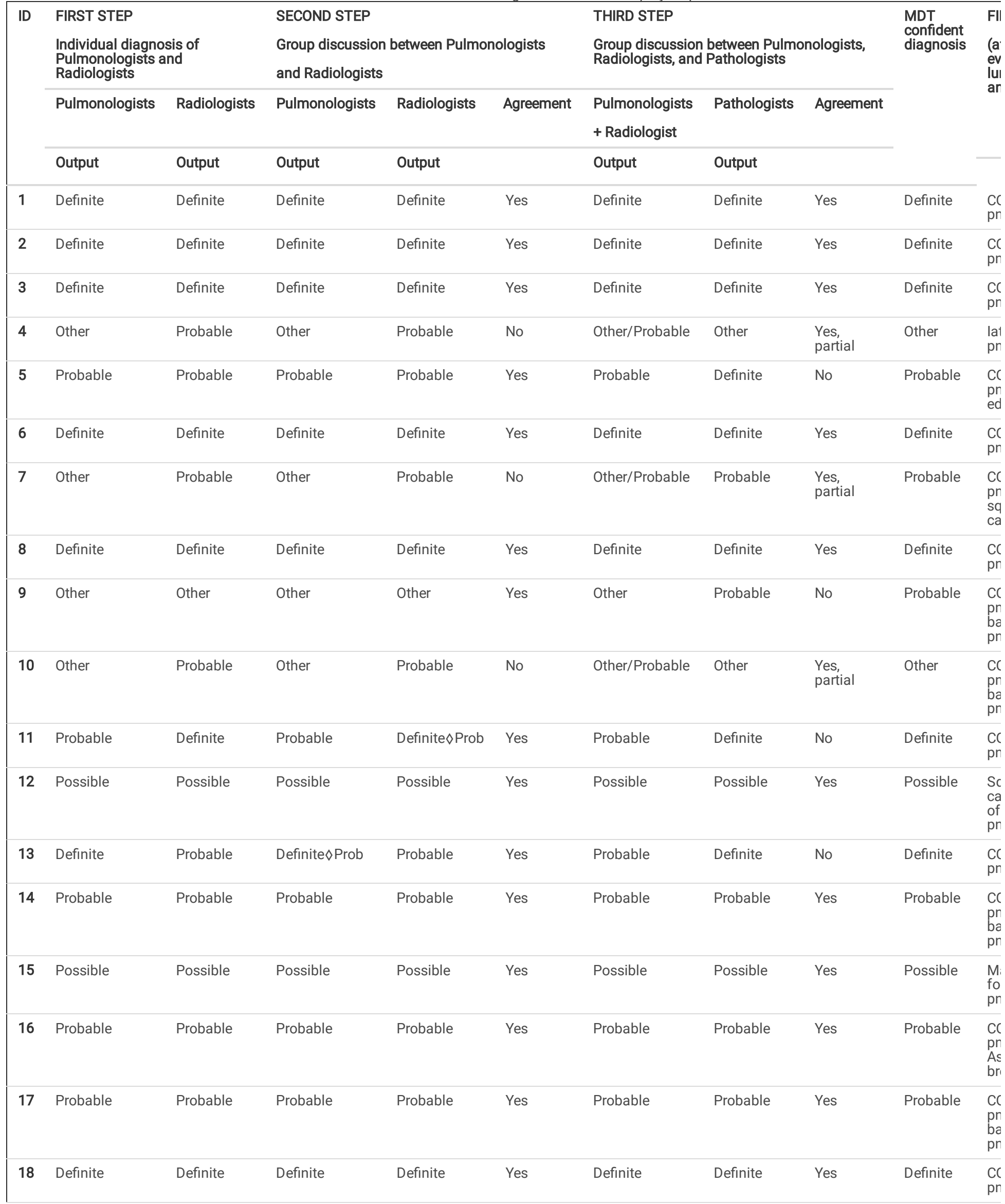




\begin{tabular}{|c|c|c|c|c|c|c|c|c|c|c|}
\hline \multirow[t]{4}{*}{ ID } & \multicolumn{2}{|c|}{$\begin{array}{l}\text { FIRST STEP } \\
\text { Individual diagnosis of } \\
\text { Pulmonologists and } \\
\text { Radiologists }\end{array}$} & \multicolumn{3}{|c|}{$\begin{array}{l}\text { SECOND STEP } \\
\text { Group discussion between Pulmonologists } \\
\text { and Radiologists }\end{array}$} & \multicolumn{3}{|c|}{$\begin{array}{l}\text { THIRD STEP } \\
\text { Group discussion between Pulmonologists, } \\
\text { Radiologists, and Pathologists }\end{array}$} & \multirow[t]{4}{*}{$\begin{array}{l}\text { MDT } \\
\text { confident } \\
\text { diagnosis }\end{array}$} & \multirow[t]{4}{*}{$\begin{array}{l}\text { Fl } \\
(a) \\
\text { ev } \\
\text { lul }\end{array}$} \\
\hline & Pulmonologists & Radiologists & Pulmonologists & Radiologists & Agreement & Pulmonologists & Pathologists & Agreement & & \\
\hline & & & & & & + Radiologist & & & & \\
\hline & Output & Output & Output & Output & & Output & Output & & & \\
\hline 19 & Definite & Other & Definite $\diamond$ Other & Other & Yes & Other & Other & Yes & Other & As \\
\hline 20 & Probable & Probable & Probable & Probable & Yes & Probable & Probable & Yes & Probable & $\mathrm{CC}$ \\
\hline 21 & Definite & Definite & Definite & Definite & Yes & Definite & Definite & Yes & Definite & $\mathrm{CC}$ \\
\hline 22 & Probable & Definite & Probable & Definite $\diamond$ Prob & Yes & Probable & Probable & Yes & Probable & $\mathrm{CC}$ \\
\hline 23 & Probable & Definite & Probable & Definite $\diamond$ Prob & Yes & Probable & Probable & Yes & Probable & $\mathrm{CC}$ \\
\hline 24 & Definite & $\mathrm{Na}$ & Definite & $\mathrm{Na}$ & $\mathrm{Na}$ & $\mathrm{Na}$ & Possible & $\mathrm{Na}$ & Possible & $\mathrm{B} \bar{c}$ \\
\hline 25 & Possible & Probable & Possible $\diamond$ Prob & Probable & Yes & Probable & Definite & No & Definite & $\mathrm{CC}$ \\
\hline 26 & Definite & Definite & Definite & Definite & Yes & Definite & Definite & Yes & Definite & $\mathrm{CC}$ \\
\hline 27 & Probable & Probable & Probable & Probable & Yes & Probable & Probable & Yes & Probable & $\mathrm{CC}$ \\
\hline
\end{tabular}

Abbreviations. na: not available; Prob: probable; SFT: solitary fibrous tumour

During the second step (Discussion between Radiologists and Pulmonologists), a confident diagnosis was reached in 23 out of 26 cases (88\%) with definite COVID-19 pneumonia in 8 cases (30\%). Following discussion, the diagnosis was changed in 6 cases, 3 changes for each specialist group (changes indicated with arrows in Table 2).

In the third step (Group discussion involving Radiologists, Pulmonologists, and Pathologists), the pathologists reported a diagnosis of definite COVID-19 pneumonia in 12 cases (45\%), probable COVID-19 pneumonia in 9 cases (33\%), and possible COVID-19 pneumonia in 3 cases (11\%). Three cases were classified as non-COVID-19 pneumonia (11\%) (Table 3). A multidisciplinary discussion led to a confident diagnosis in 18 cases (69\%), a partial agreement in 3 cases (12\%), and no agreement 5 cases (19\%) (Table 2). 
Table 3

Results of lung histological examination, molecular tissue and cultural analyses

\begin{tabular}{|c|c|c|c|c|c|}
\hline \multirow[t]{2}{*}{ ID } & \multicolumn{2}{|l|}{ HISTOLOGICAL FINDINGS } & \multicolumn{2}{|c|}{ MOLECULAR TESTS } & \multirow{2}{*}{$\begin{array}{l}\text { PATHOLOGICAL } \\
\text { DIAGNOSIS }\end{array}$} \\
\hline & COVID-19 related lesions & Other lesions & $\begin{array}{l}\text { Tissue Real Time } \\
\text { RT-PCR }\end{array}$ & Culture & \\
\hline 1 & $\begin{array}{l}\text { Diffuse alveolar damage/organizing pneumonia and } \\
\text { vascular injury }\end{array}$ & & + & + & Definite \\
\hline 2 & $\begin{array}{l}\text { Diffuse alveolar damage/organizing pneumonia and } \\
\text { vascular injury }\end{array}$ & & + & na & Definite \\
\hline 3 & $\begin{array}{l}\text { Diffuse alveolar damage/organizing pneumonia and } \\
\text { vascular injury }\end{array}$ & & + & + & Definite \\
\hline 4 & No lesions & latrogenic paracetamol injury & - & na & Other \\
\hline 5 & Diffuse alveolar damage/organizing pneumonia & & + & + & Definite \\
\hline 6 & Diffuse alveolar damage/organizing pneumonia & & + & + & Definite \\
\hline 7 & $\begin{array}{l}\text { Multiple foci of diffuse alveolar damage/organizing } \\
\text { pneumonia and vascular injury }\end{array}$ & $\begin{array}{l}\text { Bronchial squamous cell } \\
\text { carcinoma }\end{array}$ & + & + & Probable \\
\hline 8 & Diffuse alveolar damage/organizing pneumonia & & + & na & Definite \\
\hline 9 & $\begin{array}{l}\text { Multiple foci of diffuse alveolar damage/organizing } \\
\text { pneumonia and vascular injury }\end{array}$ & Bacterial pneumonia & - & na & Probable \\
\hline 10 & No lesions & Bacterial pneumonia & + & na & Other \\
\hline 11 & $\begin{array}{l}\text { Diffuse alveolar damage/organizing pneumonia and } \\
\text { vascular injury }\end{array}$ & & + & na & Definite \\
\hline 12 & $\begin{array}{l}\text { Foci of diffuse alveolar damage/organizing pneumonia } \\
\text { and vascular injury }\end{array}$ & $\begin{array}{l}\text { Diffuse squamous cell } \\
\text { carcinoma }\end{array}$ & + & na & Possible \\
\hline 13 & $\begin{array}{l}\text { Diffuse alveolar damage/organizing pneumonia and } \\
\text { vascular injury }\end{array}$ & & + & na & Definite \\
\hline 14 & $\begin{array}{l}\text { Multiple foci of diffuse alveolar damage/organizing } \\
\text { pneumonia and vascular injury }\end{array}$ & Bacterial pneumonia & + & + & Probable \\
\hline 15 & $\begin{array}{l}\text { Foci of diffuse alveolar damage/organizing pneumonia } \\
\text { and vascular injury }\end{array}$ & $\begin{array}{l}\text { Malignant pleural solitary fibrous } \\
\text { tumor }\end{array}$ & + & - & Possible \\
\hline 16 & $\begin{array}{l}\text { Multiple foci of diffuse alveolar damage/organizing } \\
\text { pneumonia and vascular injury }\end{array}$ & $\begin{array}{l}\text { Aspergillus invasive } \\
\text { bronchopneumonia }\end{array}$ & + & + & Probable \\
\hline 17 & $\begin{array}{l}\text { Multiple foci of diffuse alveolar damage/organizing } \\
\text { pneumonia and vascular injury }\end{array}$ & Bacterial pneumonia & + & - & Probable \\
\hline 18 & $\begin{array}{l}\text { Diffuse alveolar damage/organizing pneumonia and } \\
\text { vascular injury }\end{array}$ & & + & - & Definite \\
\hline 19 & No lesions & Aspiration/bacterial pneumonia & - & - & Other \\
\hline 20 & $\begin{array}{l}\text { Multiple foci of diffuse alveolar damage/organizing } \\
\text { pneumonia and vascular injury }\end{array}$ & Necrotizing granulomas & + & + & Probable \\
\hline 21 & Diffuse alveolar damage/organizing pneumonia & & + & - & Definite \\
\hline 22 & $\begin{array}{l}\text { Multiple foci of diffuse alveolar damage/organizing } \\
\text { pneumonia and vascular injury }\end{array}$ & Aspiration pneumonia & + & + & Probable \\
\hline 23 & $\begin{array}{l}\text { Multiple foci of diffuse alveolar damage/organizing } \\
\text { pneumonia and vascular injury }\end{array}$ & Bacterial pneumonia & + & - & Probable \\
\hline 24 & $\begin{array}{l}\text { Foci of diffuse alveolar damage/organizing pneumonia } \\
\text { and vascular injury }\end{array}$ & Bacterial pneumonia & + & - & Possible \\
\hline 25 & $\begin{array}{l}\text { Diffuse alveolar damage/organizing pneumonia and } \\
\text { vascular injury }\end{array}$ & & + & - & Definite \\
\hline 26 & $\begin{array}{l}\text { Diffuse alveolar damage/organizing pneumonia and } \\
\text { vascular injury }\end{array}$ & & + & + & Definite \\
\hline 27 & $\begin{array}{l}\text { Multiple foci of diffuse alveolar damage/organizing } \\
\text { pneumonia and vascular injury }\end{array}$ & $\begin{array}{l}\text { Breast cancer } \\
\text { metastases/bacterial pneumonia }\end{array}$ & + & - & Probable \\
\hline
\end{tabular}

Additional data derived from examination of the entire lungs and other organs allowed us to finally reach a shared confident diagnosis in all cases. In 2 cases (8\%), COVID-19 pneumonia was ruled out, while in 3 cases (11\%), COVID-19 pneumonia was only a marginal pathological process compared to other pathological lesions (Table 2). Examples of definite, probable, possible, and non-COVID-19 pneumonia are given in Fig. 3. 
The comparison between the diagnosis made by each specialist and the diagnosis made by the team following discussion and with the availability of the autopsy data showed that the ability to formulate a correct diagnosis increased strikingly from a non-pulmonologist to expert specialists, becoming progressively more accurate at different steps (Table 4). The GEE model showed that every single specialist was able to make a significantly more accurate diagnosis than a non-pulmonologist. The highest level of accuracy was achieved by the combination of 3 expert specialists ( $p=0.0003)$ who made diagnoses that were about 35 times more accurate [OR: 35.2 (95\% Cl: 5.07-244)] than a single non-pulmonologist (Table 5, Fig. 3). Indeed, in only 1 case (4\%, case number 10) the multidisciplinary team diagnosis was wrong when compared to the gold standard (full autopsy diagnosis) (Table 5, Fig. 3). In contrast, the diagnosis formulated by a non-pulmonologist was incorrect in over half of the cases (59\%), whereas the diagnosis formulated by a pulmonologist or a thoracic radiologist was not correct in 7 (26\%) and 6 cases (23\%), respectively. After discussion, radiologists and pulmonologists incorrectly diagnosed five cases (19\%). After a full autopsy and whole lung examination, pathologists misinterpreted two cases (7\%).

Table 4

Right and wrong diagnoses by each individual specialist and their combination

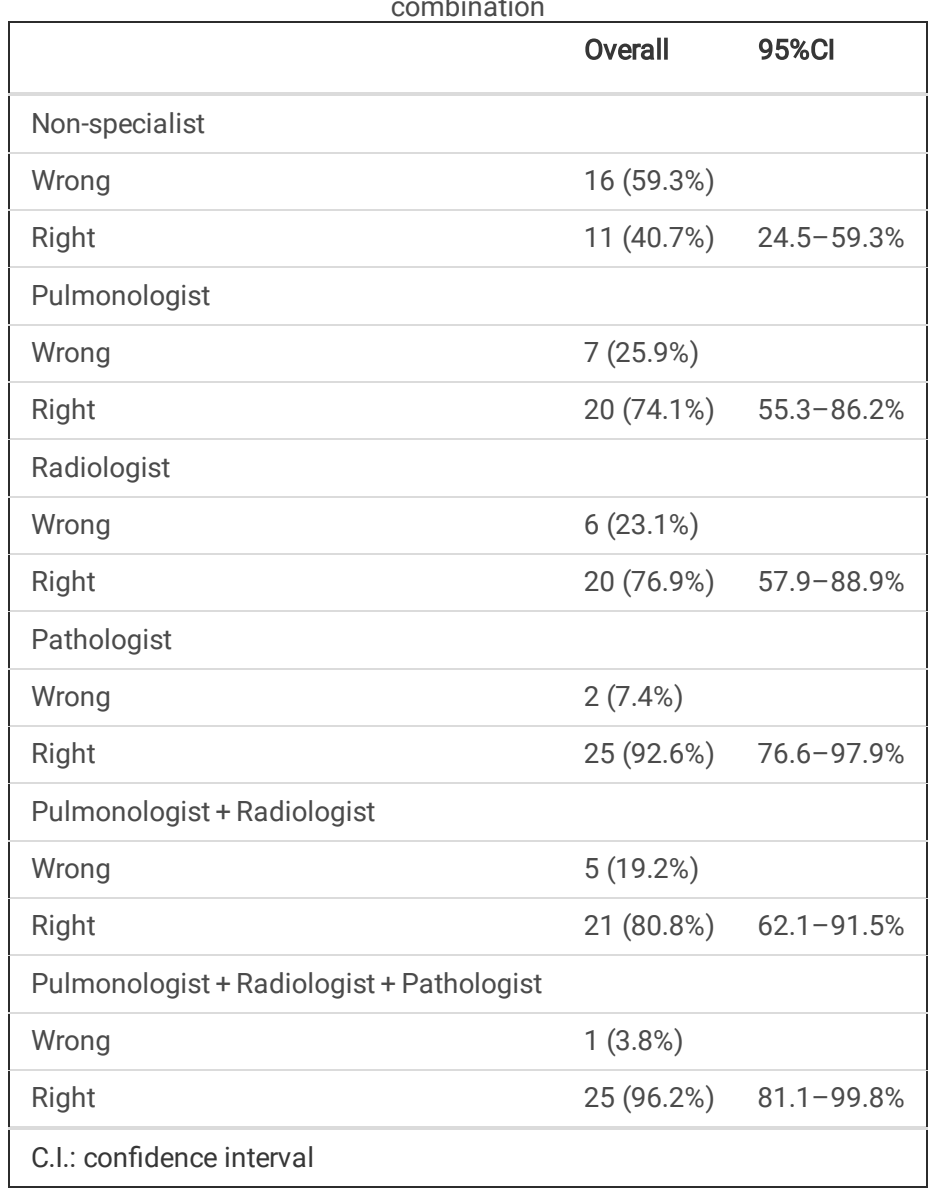

Table 5

GEE model for estimating the relative correctness of specialists in respect to the non-specialist

\begin{tabular}{|lclll|}
\hline & Estimate & Standard error & p value & $95 \% \mathrm{Cl}$ \\
\hline Pulmonologist & 4.14 & 0.540 & 0.0084 & $1.44-12.0$ \\
\hline Radiologist & 4.80 & 0.574 & 0.0063 & $1.56-14.8$ \\
\hline Pathologist & 20.5 & 0.821 & 0.0002 & $4.09-102$ \\
\hline Pulmonologist + Radiologist & 6.33 & 0.691 & 0.0075 & $1.63-24.5$ \\
\hline Pulmonologist + Radiologist + Pathologist & 35.2 & 0.989 & 0.0003 & $5.07-244$ \\
\hline C.l.: confidence interval & & & & \\
\hline
\end{tabular}

\section{Discussion}

In this study, we showed that the diagnostic accuracy of a multidisciplinary approach involving dedicated DPLD physicians is significantly higher than that of non-pulmonologists in a subset of patients infected by SARS-CoV-2 who died at the University Hospital of Padova and who underwent autopsy. We demonstrated that the dynamic interaction among DPLD experts influenced the level of confidence for the final diagnosis, which improved step by step. In two cases (8\%), the diagnosis of COVID-19-related death was incorrect (final diagnosis: no COVID-19 pneumonia), while in three cases (11\%), COVID-19 
pneumonia was only a marginal feature compared to other pathological lesions. Thus, in $19 \%$ of cases the diagnosis was mainly incorrect with consequent inappropriate patient management. This was the case in two patients, one with severe aspiration pneumonia and the other with carcinomatous lymphangitis who would have required different monitoring and management of care. Inappropriate treatment might have impacted on patient survival and outcome.

The global spread of the SARS-CoV-2 infection was quite unexpected, rapidly leading to a worldwide health emergency. As with any pandemic, patient care has been affected by staffing shortages, a chaotic work environment, and high levels of clinician stress. Clinicians had no choice but to provide care in an extraordinary setting. Moreover, the ICUs rapidly became saturated, and their overcrowding led to the recruitment of non-specialist medical staff, potentially exposing critically ill patients to mismanagement. Based on this distressing experience, COVID-19 health care should be planned adequately during the current second global wave. Today, the challenge is to establish a correct diagnosis taking into consideration several pathological conditions that may mimic and/or overlap with COVID-19 pneumonia, with the aim of optimizing patient management and, consequently, reducing mortality. Although our study consisted of a retrospective analysis (i.e., "a backward path by an expert team"), we believe a multidisciplinary approach involving specialists with experience in DPLD diagnosis and management can be highly beneficial to patient care. The multidisciplinary evaluation has become the diagnostic gold standard for DPLD, as it improves diagnostic confidence and interobserver agreement compared to individual components of the multidisciplinary team in isolation [16, 22], as was the case in our study.

An expert team should be involved in patient evaluation at the very time of hospital admission, particularly when patients are fragile and have severe respiratory failure. The chaotic work environment and the stressful conditions of emergency medical staff, which may make a face-to-face multidisciplinary approach nonrealistic, might be successfully overcome by using newer digital technologies. Indeed, during the COVID-19 pandemic, multi-specialist meetings have been suspended and converted into virtual meetings, as occurred in our case.

In the multidisciplinary team of DPLD specialists, radiologists play a key role in that HRCT is largely recognized as a very sensitive and highly specific tool [22-24]. During the early phase of the pandemic, CT was seldom performed in COVID-19-positive patients for safety reasons [25, 26]. Although chest X-ray proved to be an accurate and reliable method to assess patients with COVID-19, even allowing the development of dedicated scores [CARE referral score] [26], CT plays a crucial role in recognizing alternative diagnoses, especially in patients with pre-existing pulmonary diseases [27-29]. The use of a diagnostic modality other than the gold standard may account for the higher agreement between pathologists and pulmonologists than radiologists in cases of partial agreement. Learning from the difficulties encountered in the first wave of the pandemic, most hospitals worldwide have recently adopted organizational models, which guarantee safe pathways to CT scanners that will surely increase the use of this technique and are expected to have a significant impact on the quality of the delivered care $[30,31]$.

In our study, as expected, pathologists showed the highest level of confidence between the first diagnostic impression on a single lung fragment compared to the final diagnosis on whole lung examination, with an incorrect diagnosis being made in only two cases. The lung fragments used by pathologists to perform the first diagnosis were similar in size to those obtained by video-assisted thoracic surgery (VATS) that is suggested to be the gold standard tool for the histological diagnosis of DPLD/ILD [24]. Invasive procedures such as VATS carry a high risk of mortality, particularly in patients with severe respiratory dysfunction and under mechanical ventilation [32]. During the SARS-CoV2 pandemic, invasive diagnostic procedures involving sampling of the lung parenchyma were discouraged. However, given the critically important contribution that pathologists could provide in the diagnosis of COVID19 pneumonia, minimally invasive procedures, such as transbronchial lung biopsy/cryobiopsy could be reconsidered in the diagnostic work-up of COVID-19 pneumonia. This is in line with recent expert recommendations [33] suggesting that bronchoscopy can be safely performed in patients with COVID-19, prioritizing minimization of the risk of viral transmission.

Information coming from a full autopsy of COVID-19 patients with the evaluation of numerous lung samples was considered the gold standard for final diagnosis in our case series. Data provided by the most recent autopsy studies have been crucial in improving our knowledge of the pathological substrates of COVID-19. Indeed, because of the contribution of autopsy studies, COVID-19 pneumonia is now recognized as a complex disease involving not only the lung parenchyma but also the vascular compartment with features that include vasculitis, angiogenesis, capillaritis, and micro/macrothrombi [10, 12, 34].

The present study has several limitations. First, the study is monocentric, and the study population is relatively small. However, despite this, we were able to implement a GEE model that is robust and provides reliable results even with small sample sizes. Moreover, this is one of the largest monocentric European case series wherein the same lung sampling methodology and analysis was consistently applied.

\section{Conclusions}

A multidisciplinary approach to diagnosis and management of patients with COVID-19 requires extra effort by the healthcare providers involved but, if it should be validated, it would have the potential to consistently improve the outcome of this often-fatal disease.

\section{List Of Abbreviations}

Coronavirus disease 2019 (COVID-19), severe acute respiratory syndrome-related coronavirus 2 (SARS-CoV-2), acute respiratory failure (ARF), intensive care unit (ICU), diffuse parenchymal lung disease (DPLD), reverse transciptase-polymerase chain reaction (RT-PCR), Centers for Disease Control and Prevention (CDC), Emergency Use Authorized (EUA), computed tomography (CT), generalized estimating equations (GEE), video-assisted thoracic surgery (VATS).

\section{Declarations}

\section{Ethics approval and consent to participate:}


The study was approved by the local Ethics Committee of the University Hospital of Padova (4853/A0/20). Informed consent was granted by a relative/legal representative of each deceased patient.

\section{Consent for publication:}

Not applicable.

\section{Availability of data and materials:}

The datasets used and/or analysed during the current study are available from the corresponding author on reasonable request.

\section{Competing interests:}

The authors declare no competing interests.

\section{Funding:}

This research did not receive any specific grant from funding agencies in the public or commercial.

\section{Authors' contributions:}

Fiorella Calabrese, Elisabetta Balestro, Paolo Spagnolo: conceptualization, writing-reviewing and editing, supervision; Federica Pezzuto, Francesco Fortarezza, Chiara Giraudo: writing original draft-preparation, visualization, investigation; Francesca Lunardi, Elisabetta Cocconcelli, Luca Vedovelli, Stefania Edith Vuljan, Claudia Del Vecchio, Anna Sara Fraia: resources, investigation; Dario Gregori, Andrea Crisanti: resources, investigation, visualization, supervision. All authors have read and approved the final version of the manuscript.

\section{Acknowledgements:}

The authors thank Dr. Judith Wilson for English-language revision.

\section{References}

1. Coronaviridae Study Group Of The International Committee On Taxonomy Of Viruses. The Species Severe Acute Respiratory Syndrome-Related Coronavirus: Classifying 2019-Ncov And Naming It SARS-Cov-2. Nature Microbiology 2020; 5: 536-544. doi: 10.1038/s41564-020-0695-z.

2. Yang X, Yu Y, Xu J, Shu H, Xia J, Liu H, Wu Y, Zhang L, Yu Z, Fang M, Yu T, Wang Y, Pan S, Zou X, Yuan S, Shang Y. Clinical Course And Outcomes Of Critically III Patients With SARS-Cov-2 Pneumonia In Wuhan, China: A Single-Centered, Retrospective, Observational Study. Lancet Respir Med 2020; 8:475481. doi: 10.1016/S2213-2600(20)30079-5.

3. Rello J, Storti E, Belliato M, Serrano R. Clinical Phenotypes Of SARS-Cov-2: Implications For Clinicians And Researchers. Eur Respir J 2020; 55 : 2001028. doi: 10.1183/13993003.01028-2020.

4. Grasselli G, Tonetti T, Protti A, Langer T, Girardis M, Bellani G, Laffey J, Carrafiello G, Carsana L, Rizzuto C, Zanella A, Scaravilli V, Pizzilli G, Grieco DL, Di Meglio L, De Pascale G, Lanza E, Monteduro F, Zompatori M, Filippini C, Locatelli F, Cecconi M, Fumagalli R, Nava S, Vincent JL, Antonelli M, Slutsky AS, Pesenti A, Ranieri VM; Collaborators. Pathophysiology Of COVID-19-Associated Acute Respiratory Distress Syndrome: A Multicentre Prospective Observational Study. Lancet Respir Med 2020; 27: S2213-2600(20)30370-2. doi: 10.1016/S2213-2600(20)30370-2.

5. Figliozzi S, Masci PG, Ahmadi N, Tondi L, Koutli E, Aimo A, Stamatelopoulos K, Dimopoulos MA, Caforio ALP, Georgiopoulos G. Predictors Of Adverse Prognosis In COVID-19: A Systematic Review And Meta-Analysis. Eur J Clin Invest 2020; 50: E13362. doi: 10.1111/eci.13362.

6. Porcheddu R, Serra C, Kelvin D, Kelvin N, Rubino S. Similarity In Case Fatality Rates (CFR) Of COVID-19/SARS-COV-2 In Italy And China. J Infect Dev Ctries 2020; 14: 125-128. doi: 10.3855/jidc. 12600.

7. Raghu G, Remy-Jardin M, Myers JL, Richeldi L, Ryerson CJ, Lederer DJ, Behr J, Cottin V, Danoff SK, Morell F, Flaherty KR, Wells A, Martinez FJ, Azuma A, Bice TJ, Bouros D, Brown KK, Collard HR, Duggal A, Galvin L, Inoue Y, Jenkins RG, Johkoh T, Kazerooni EA, Kitaichi M, Knight SL, Mansour G, Nicholson AG, Pipavath SNJ, Buendía-Roldán I, Selman M, Travis WD, Walsh S, Wilson KC; American Thoracic Society, European Respiratory Society, Japanese Respiratory Society, And Latin American Thoracic Society. Diagnosis Of Idiopathic Pulmonary Fibrosis. An Official ATS/ERS/JRS/ALAT Clinical Practice Guideline. Am J Respir Crit Care Med 2018 1; 198: E44-E68. doi: 10.1164/rccm.201807-1255ST.

8. Cocconcelli E, Balestro E, Biondini D, Barbiero G, Polverosi R, Calabrese F, Pezzuto F, Lacedonia D, Rea F, Schiavon M, Bazzan E, Foschino Barbaro MP, Turato G, Spagnolo P, Cosio MG, Saetta M. High-Resolution Computed Tomography (HRCT) Reflects Disease Progression In Patients With Idiopathic Pulmonary Fibrosis (IPF): Relationship With Lung Pathology. J Clin Med. 2019; 8: 399. doi: 10.3390/jcm8030399.

9. Cocconcelli E, Biondini D, Giraudo C, Lococo S, Bernardinello N, Fichera G, Barbiero G, Castelli G, Cavinato S, Ferrari A, Saetta M, Cattelan A, Spagnolo P, Balestro E. Clinical Features and Chest Imaging as Predictors of Intensity of Care in Patients with COVID-19. J Clin Med 2020; 9: 2990. doi: 
10.3390/jcm9092990.

10. Borczuk AC, Salvatore SP, Seshan SV, Patel SS, Bussel JB, Mostyka M, Elsoukkary S, He B, Del Vecchio C, Fortarezza F, Pezzuto F, Navalesi P, Crisanti A, Fowkes ME, Bryce CH, Calabrese F, Beasley MB. COVID-19 Pulmonary Pathology: A Multi-Institutional Autopsy Cohort From Italy And New York City. Mod Pathol 2020; 33: 2156-2168. doi: 10.1038/s41379-020-00661-1.

11. Lavezzo E, Franchin E, Ciavarella C, Cuomo-Dannenburg G, Barzon L, Del Vecchio C, Rossi L, Manganelli R, Loregian A, Navarin N, Abate D, Sciro M, Merigliano S, De Canale E, Vanuzzo MC, Besutti V, Saluzzo F, Onelia F, Pacenti M, Parisi SG, Carretta G, Donato D, Flor L, Cocchio S, Masi G, Sperduti A, Cattarino L, Salvador R, Nicoletti M, Caldart F, Castelli G, Nieddu E, Labella B, Fava L, Drigo M, Gaythorpe KAM; Imperial College COVID-19 Response Team, Brazzale AR, Toppo S, Trevisan M, Baldo V, Donnelly CA, Ferguson NM, Dorigatti I, Crisanti A. Suppression Of A SARS-Cov-2 Outbreak In The Italian Municipality Of Vo'. Nature 2020; 584: 425-429. doi: 10.1038/s41586-020-2488-1.

12. Calabrese F, Pezzuto F, Fortarezza F, Hofman P, Kern I, Panizo A, Von Der Thüsen J, Timofeev S, Gorkiewicz G, Lunardi F. Pulmonary Pathology And COVID19: Lessons From Autopsy. The Experience Of European Pulmonary Pathologists. Virchows Arch 2020; 477: $359-372$.

13. Huang C, Wang Y, Li X, Ren L, Zhao J, Hu Y, Zhang L, Fan G, Xu J, Gu X, Cheng Z, Yu T, Xia J, Wei Y, Wu W, Xie X, Yin W, Li H, Liu M, Xiao Y, Gao H, Guo L, Xie J, Wang G, Jiang R, Gao Z, Jin Q, Wang J, Cao B. Clinical Features Of Patients Infected With 2019 Novel Coronavirus In Wuhan, China. Lancet 2020; 395: 497-506. Erratum In: Lancet. 2020 Jan 30. doi: 10.1007/s00428-020-02886-6.

14. Guan WJ, Ni ZY, Hu Y, Liang WH, Ou CQ, He JX, Liu L, Shan H, Lei CL, Hui DSC, Du B, Li LJ, Zeng G, Yuen KY, Chen RC, Tang CL, Wang T, Chen PY, Xiang J, Li SY, Wang JL, Liang ZJ, Peng YX, Wei L, Liu Y, Hu YH, Peng P, Wang JM, Liu JY, Chen Z, Li G, Zheng ZJ, Qiu SQ, Luo J, Ye CJ, Zhu SY, Zhong NS; China Medical Treatment Expert Group For Covid-19. Clinical Characteristics Of Coronavirus Disease 2019 In China. N Engl J Med 2020; 382: 1708-1720. doi: 10.1056/NEJMoa2002032.

15. Kanne JP, Little BP, Chung JH, Elicker BM, Ketai LH. Essentials For Radiologists On COVID-19: An Update-RadiologyScientific Expert Panel. Radiology 2020; 296: E113-E114. doi: 10.1148/radiol.2020200527.

16. Flaherty KR, King TE Jr, Raghu G, Lynch JP 3rd, Colby TV, Travis WD, Gross BH, Kazerooni EA, Toews GB, Long Q, Murray S, Lama VN, Gay SE, Martinez FJ. Idiopathic Interstitial Pneumonia: What Is The Effect Of A Multidisciplinary Approach To Diagnosis? Am J Respir Crit Care Med 2004; 170: 904-10. doi: 10.1164/rccm.200402-1470C.

17. Harrell FE, With Contributions From Dupont C, And Many Others, Hmisc: Harrell Miscellaneous. 2020.

18. Højsgaard S, Halekoh U, Yan J. The R Package Geepack For Generalized Estimating Equations. J Stat Softw Artic 2015; $15:$ 1-11.

19. Hardin JW. Generalized Estimating Equations (GEE) In Encyclopedia Of Statistics In Behavioral Science, American Cancer Society, 2005

20. Halekoh U, Højsgaard S, Yan J. The R Package Geepack For Generalized Estimating Equations. J Stat Softw 2006; 15.

21. R Core Development Team. R: A Language And Environment For Statistical Computing. Vienna, Austria. 2019.

22. Raghu G, Collard HR, Egan JJ, Martinez FJ, Behr J, Brown KK, Colby TV, Cordier JF, Flaherty KR, Lasky JA, Lynch DA, Ryu JH, Swigris JJ, Wells AU, Ancochea J, Bouros D, Carvalho C, Costabel U, Ebina M, Hansell DM, Johkoh T, Kim DS, King TE Jr, Kondoh Y, Myers J, Müller NL, Nicholson AG, Richeldi L, Selman M, Dudden RF, Griss BS, Protzko SL, Schünemann HJ; ATS/ERS/JRS/ALAT Committee On Idiopathic Pulmonary Fibrosis. An Official ATS/ERS/JRS/ALAT Statement: Idiopathic Pulmonary Fibrosis: Evidence-Based Guidelines For Diagnosis And Management. Am J Respir Crit Care Med 2011; 183:788-824. doi: 10.1164/rccm.2009-040GL.

23. Desai SR, Prosch H, Galvin JR. Plain Film And HRCT Diagnosis Of Interstitial Lung Disease. 2019 Feb 20. In: Hodler J, Kubik-Huch RA, Von Schulthess GK, Editors. Diseases Of The Chest, Breast, Heart And Vessels 2019-2022: Diagnostic And Interventional Imaging [Internet]. Cham (CH): Springer; 2019. Chapter 4.

24. Lynch DA, Sverzellati N, Travis WD, Brown KK, Colby TV, Galvin JR, Goldin JG, Hansell DM, Inoue Y, Johkoh T, Nicholson AG, Knight SL, Raoof S, Richeldi L, Ryerson CJ, Ryu JH, Wells AU. Diagnostic Criteria For Idiopathic Pulmonary Fibrosis: A Fleischner Society White Paper. Lancet Respir Med 2018;6: 138153. doi: 10.1016/S2213-2600(17)30433-2.

25. Fichera G, Stramare R, De Conti G, Motta R, Giraudo C. It's Not Over Until It's Over: The Chameleonic Behavior Of COVID-19 Over A Six-Day Period. Radiol Med 2020; 125: 514-516. doi: 10.1007/s11547-020-01203-0.

26. Giraudo C, Cavaliere A, Fichera G, Weber M, Motta R, Pelloso M, Tosato F, Lupi A, Calabrese F, Carrett G, Cattelan A, Deconti G, Cianci V, Navalesi P, Plebani M, Rea F, Vettor R, Vianello A, Stramare R. Validation Of A Composed COVID-19 Chest Radiography Score: The CARE Project. ERJ Open Research 2020; 6: 00359-2020. doi: 10.1183/23120541.00359-2020

27. Larici AR, Cicchetti G, Marano R, Merlino B, Elia L, Calandriello L, Del Ciello A, Farchione A, Savino G, Infante A, Larosa L, Colosimo C, Manfredi R, Natale L. Multimodality Imaging Of COVID-19 Pneumonia: From Diagnosis To Follow-Up. A Comprehensive Review. Eur J Radiol 2020; 131: 109217. doi: 10.1016/j.ejrad.2020.109217.

28. Rubin GD, Ryerson CJ, Haramati LB, Sverzellati N, Kanne JP, Raoof S, Schluger NW, Volpi A, Yim JJ, Martin IBK, Anderson DJ, Kong C, Altes T, Bush A, Desai SR, Goldin J, Goo JM, Humbert M, Inoue Y, Kauczor HU, Luo F, Mazzone PJ, Prokop M, Remy-Jardin M, Richeldi L, Schaefer-Prokop CM, Tomiyama $\mathrm{N}$, Wells AU, Leung AN. The Role Of Chest Imaging In Patient Management During The COVID-19 Pandemic: A Multinational Consensus Statement From The Fleischner Society. Chest 2020; 158: 106-116. doi: 10.1016/j.chest.2020.04.003.

29. AkI EA, Blazic I, Yaacoub S, Frija G, Chou R, Appiah JA, Fatehi M, Flor N, Hitti E, Jafri H, Jin ZY, Kauczor HU, Kawooya M, Kazerooni EA, Ko JP, Mahfouz R, Muglia V, Nyabanda R, Sanchez M, Shete PB, Ulla M, Zheng C, Van Deventer E, Perez MDR. Use Of Chest Imaging In The Diagnosis And Management Of COVID-19: A WHO Rapid Advice Guide. Radiology 2020; 30:203173. doi: 10.1148/radiol.2020203173.

30. Mossa-Basha M, Medverd J, Linnau KF, Lynch JB, Wener MH, Kicska G, Staiger T, Sahani DV. Policies And Guidelines For COVID-19 Preparedness: Experiences From The University Of Washington. Radiology 2020; 296: E26-E31. doi: 10.1148/radiol.2020201326. 
31. Cester G, Giraudo C, Causin F, Boemo DG, Anglani M, Capizzi A, Carretta G, Cattelan A, Cecchin D, Cianci V, Crisanti A, De Conti G, Donato D, Flor L, Gabrieli JD, Munari M, Navalesi P, Ponzoni A, Scapellato ML, Tiberio I, Vianello A, Stramare R. Retrospective Analysis Of A Modified Organizational Model To Guarantee CT Workflow During The COVID-19 Outbreak In The Tertiary Hospital Of Padova, Italy. J Clin Med 2020; 9: 3042. doi: 10.3390/jcm9093042.

32. Ghatol A, Ruhl AP, Danoff SK. Exacerbations In Idiopathic Pulmonary Fibrosis Triggered By Pulmonary And Nonpulmonary Surgery: A Case Series And Comprehensive Review Of The Literature. Lung 2012; 190: 373-80. doi: 10.1007/s00408-012-9389-5.

33. Luo F, Darwiche K, Singh S, Torrego A, Steinfort DP, Gasparini S, Liu D, Zhang W, Fernandez-Bussy S, Herth FJF, Shah PL. Performing Bronchoscopy In Times Of The COVID-19 Pandemic: Practice Statement From An International Expert Panel. Respiration 2020; 9: 417-422. doi: 10.1159/000507898.

34. Calabrese F, Fortarezza F, Giraudo C, Pezzuto F, Faccioli E, Rea F, Pittarello D, Correale C, Navalesi P. Two Sorts Of Microthrombi In A Patient With Coronavirus Disease 2019 And Lung Cancer. J Thorac Oncol 2020; 15: 1782-1785. doi: 10.1016/j.jtho.2020.08.008.

\section{Figures}

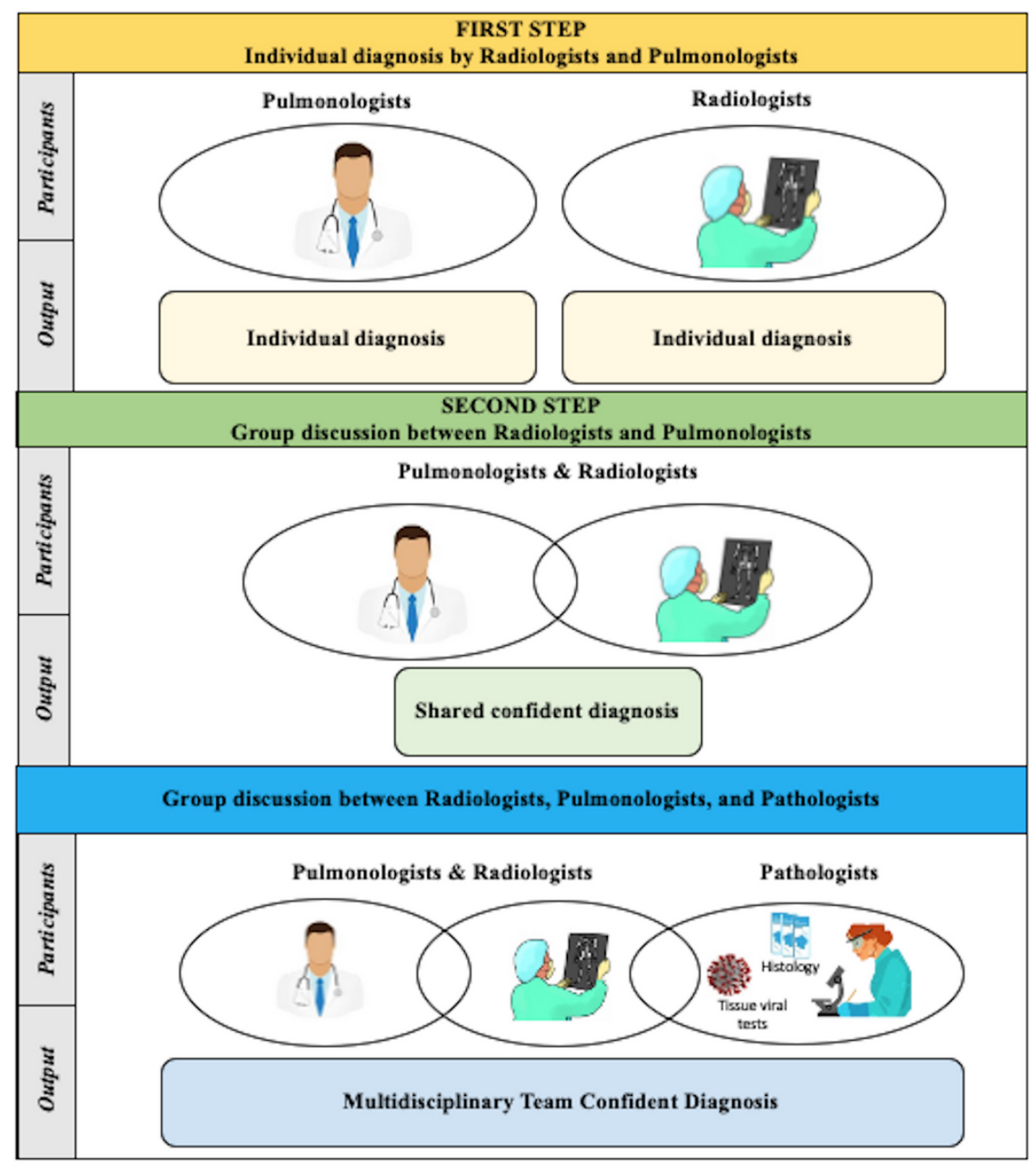

Figure 1

Graphic representation of multistep processing in the decision-making approach. 


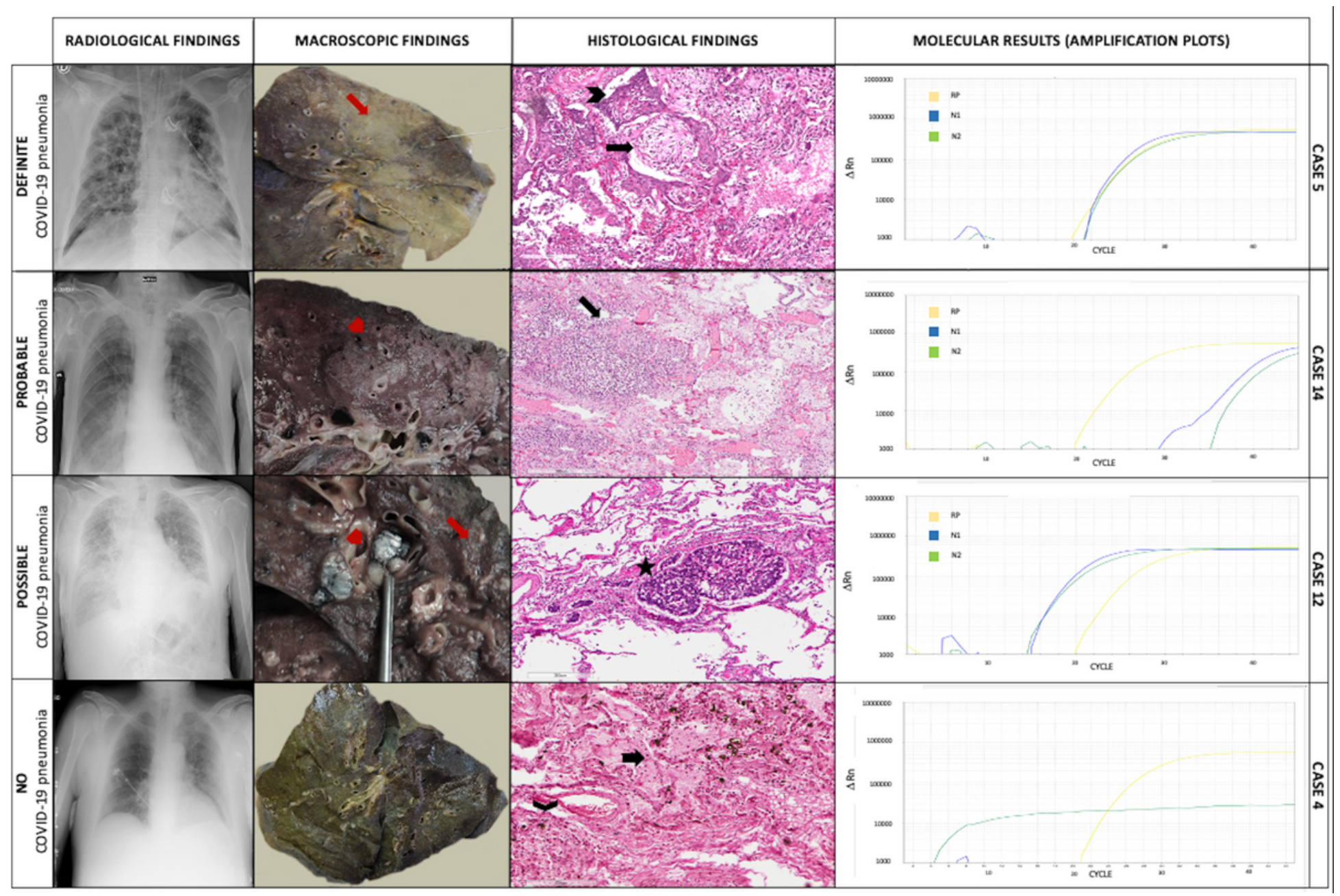

Figure 2

Explicative cases of definite, probable, possible, and non-COVID-19 pneumonia. In case 5, chest X-ray showed diffuse, bilateral ground-glass and interstitial opacities and pulmonary consolidations. The gross examination showed diffuse lung parenchyma consolidation (formalin-fixed lung, red arrow). At histology, multiple foci of diffuse alveolar damage and organizing pneumonia were seen (black arrow) with squamous metaplasia (black arrowhead). Hematoxylineosin, scale bar: $200 \mu \mathrm{m}$. Tissue molecular analysis for SARS-CoV-2 was positive. In case 14, chest X-ray demonstrated ground-glass opacities and pleural effusion. The gross examination showed a greyish granular and friable area in the lung (red arrowhead). At histology areas of granulocyte, infiltration with abscess-like features was seen (bacterial pneumonia, black arrow). Hematoxylin-eosin, scale bar: $300 \mu$ m. Tissue molecular analysis for SARS-CoV-2 was positive. In case 12, chest X-ray showed signs of pulmonary vascular congestion, interstitial thickening, ground-glass opacities, bilateral pulmonary consolidations, and pleural effusion. The gross examination showed nodular lymphangitis and lymph node metastasis (red arrow). At histology multiple foci of neoplastic thrombi of squamous cell carcinoma were seen (black star). Hematoxylin-eosin, scale bar: $300 \mu \mathrm{m}$. Tissue molecular analysis for SARS-CoV-2 was positive. In case 4, chest X-ray demonstrated bilateral signs of pulmonary vascular congestion and ground-glass opacities in the left lung. Gross examination showed the lung with a greenish/brown appearance (formalin-fixed lung). At histology, edema (black arrow) and diffuse infiltration of macrophages with intracytoplasmic bile pigment granules (black arrowhead) were detected. Hematoxylin eosin, scale bar: $200 \mu \mathrm{m}$. Tissue molecular analysis for SARS-CoV-2 was negative. Abbreviations: $\Delta \mathrm{Rn}$ (the normalized reporter value $(\mathrm{Rn})$ of the experimental reaction minus the $\mathrm{Rn}$ value of the baseline signal generated by the instrument); RP (human RNase P gene); N1 (region of virus nucleocapsid); N2 (region of virus nucleocapsid). 


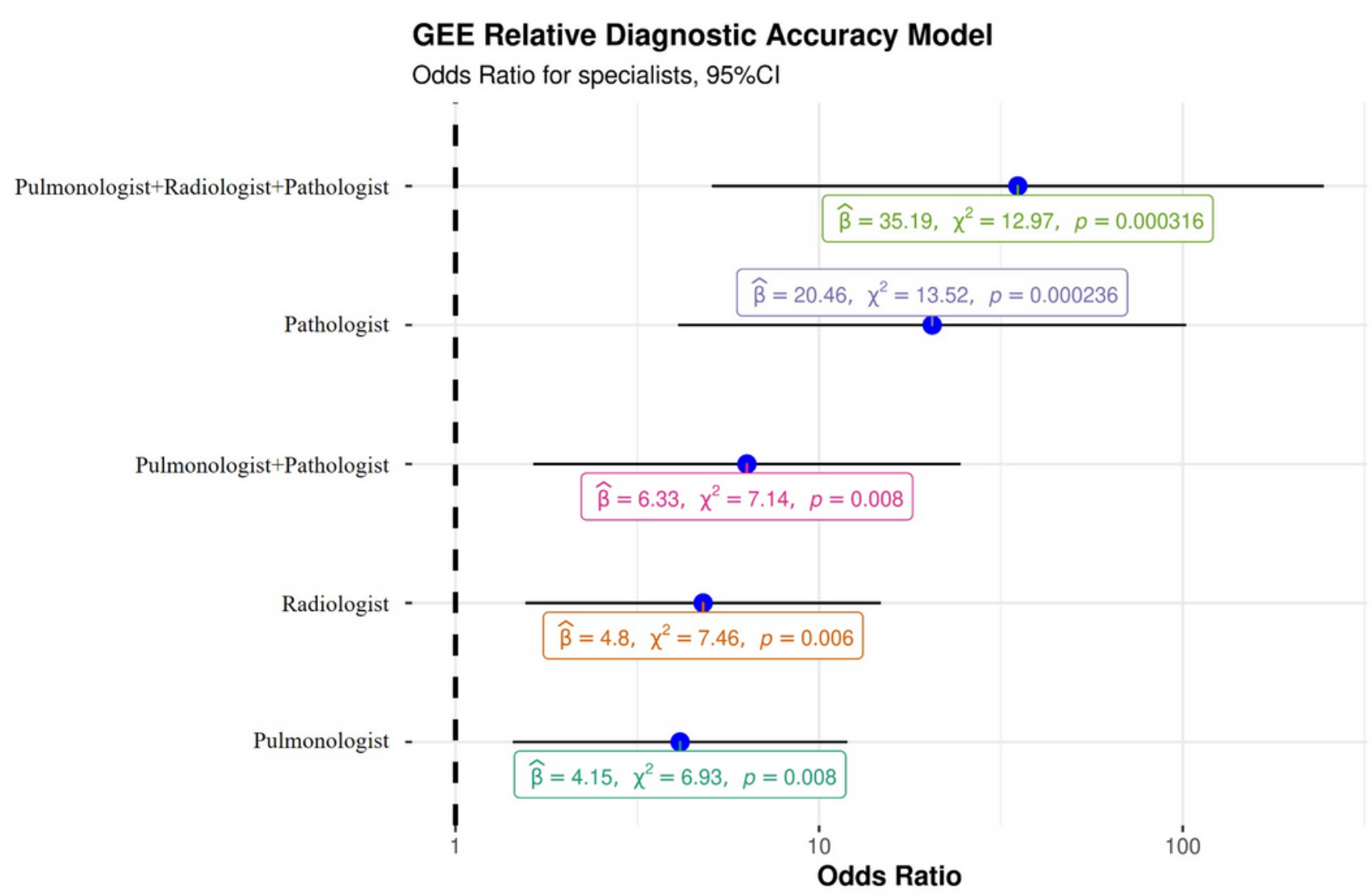

Figure 3

Generalized estimating equation representing the probability of a correct diagnosis for single specialists and for the multidisciplinary team. Abbreviations: $\beta$ (beta, "estimate"), \2 (chi-squared, "regression coefficient"). 